\title{
A crise estrutural do capitalismo e o irracionalismo
}

\author{
Belmira Magalhães ${ }^{1}$
}

\begin{abstract}
The logic of capitalist production is subject to a contradiction in which each production process produces the need for greater consumption. Its way of valuing capital is the exploitation of labor, always lowering the value of labor through the preclusion of the working-class consumption of goods that in turn prevents the flow of the entire production. The development of this contradiction, which generated the structural crisis of capitalism, demonstrates the inability of capitalist logic to reinvigorate itself without direct intervention in labor legislation. Other measures are also activated, such as wars and interventions in other countries. Parallel to this, irrationalism becomes the way in which the bourgeoisie creates and exposes its ideas necessary to maintain the order of the system that has determined their class as dominant. In this respect, nothing that the bourgeoisie practices should seem like a novelty to those who have a radical critical view of social relations in the capitalist system. The alienation that arises from the very logic of capital and from the role of ideology creates the necessary scene for the implementation of "changes" that cannot but be consolidated for the whole of society, but which do not interest the workers. They end up being carried out under the guise of charismatic proposals made in times of elections and always in the name of democracy. In this way, democracy has become an exchange of personal benefits among politicians. Following this logic, it must be understood that the political crisis that arises after the re-election of President Dilma is one of the consequences of the structural crisis of capital. It is a political crisis that does not stand on its own, but dialectically interferes with the measures to be taken by the State with discourses to "save" the Brazilian economy.
\end{abstract}

Keywords: capitalism; politics; irrationalism.

Resumo: A lógica da produção capitalista está submetida a uma contradição que a cada maior produção produz a necessidade de maior consumo, sua forma de valorizar seu capital é a exploração do trabalho, baixando sempre o valor do trabalho, que inviabiliza o consumo dele, impedindo o escoamento de toda a produção. O desenvolvimento dessa contradição gerou a crise estrutural do capitalismo e demonstra a incapacidade da lógica capitalista de se revigorar sem uma intervenção direta nas leis trabalhistas. Outras formas também são ativadas como as guerras e as intervenções em países. Paralelamente, o irracionalismo se torna a forma com que a burguesia cria e expõe suas ideias necessárias à manutenção da ordem do sistema que lhe determinou a sua classe como dominante. Nesse sentido, nada que a burguesia efetive deve ser novidade para aqueles que têm uma

1 Profa. Titular e docente do Programa de Pós-Graduação em Letras da Universidade Federal de Alagoas. 
visão crítica radical sobre as relações sociais no sistema capitalista. A alienação decorrente da própria lógica do capital e do papel da ideologia criam a cena necessária para a implementação de "mudanças" que não podem deixar de se consolidar para toda a sociedade, mas que não interessam aos trabalhadores. Elas acabam sendo efetivadas sob a roupagem de propostas carismáticas feitas em épocas de eleições mediante os órgãos políticos, e sempre em nome da democracia. Dessa forma, a democracia se tornou uma troca de benefícios pessoais entre os políticos. Seguindo essa lógica, há de se entender que a crise política que se instala após a reeleição da presidenta Dilma é uma das consequências de mais uma crise do capital; ela não se põe por si mesma, mas dialeticamente interfere nas medidas a serem tomadas pelo Estado, no discurso para "salvar" a economia brasileira.

Palavras-chave: capitalismo; política; irracionalismo.

\section{Introdução}

Neste artigo discutiremos as condições econômicas e políticas que fazem parte da lógica capitalista.

Faz parte da estrutura dessa lógica a convivência com crises geradas pelo desequilíbrio entre produção, circulação e consumo. No início do capitalismo, as crises eram cíclicas e muitas vezes localizadas, na medida em que havia muito crescimento possível ainda para ocorrer. $\mathrm{O}$ uso das guerras mostra isto de forma bastante clara.

$\mathrm{O}$ desenvolvimento das forças de produção capitalistas, principalmente tecnológicas e da globalização, e a necessidade do próprio sistema de expandir seus mercados e explorar mão de obra mais barata dos países subdesenvolvidos e dos em desenvolvimento permitiam um crescimento através da expansão. No entanto, essas estratégias não são ilimitadas, pois enfraquecem os Estados desenvolvidos e acabam por aniquilar os países subdesenvolvidos. Os mercados se desiquilibram sempre, tornando evidente que aquilo que era tido como algo que ocorria por diferentes causas é estrutural. Isso faz parte da lógica capitalista.

Há, então, uma mudança de formas que vem sendo observada desde o século 20 e se expande no século 21 .

A democracia como forma exemplar das economias desenvolvidas não é mais vista como a forma correta para esses países. O real da história nos mostra esse fato nos movimentos de trabalhadores da Europa, no caos da política americana, no empobrecimento dos países em desenvolvimento, como em alguns da América, inclusive o Brasil, que apresentam uma democracia eleitoral e uma onda conservadora na cultura, bem como concordância com as propostas dos Estados Unidos de voltar a ser um país agroexportador, o que gera um desemprego enorme e um grande número de empregos informais.

Vivem-se na contemporaneidade novas relações políticas, repressão e mais exploração dos trabalhadores.

\section{A lógica capitalista}

As primeiras aproximações que este texto precisa fazer se referem à necessidade de discutir as condições de produção que determinam o momento histórico que se está vivendo no mundo e, especialmente, no Brasil. 
A chamada globalização nada mais é do que um discurso construído pelos ideólogos do capitalismo com o objetivo de criar um efeito discursivo de que não há um centro de poder no mundo, de que todos os países, de formas diferentes, participam da engrenagem e mantêm o mundo em movimento, sem um centro que controle esse movimento. Uma forma ideológica para se afastar da noção de imperialismo. Embora não seja a mesma coisa, pois as condições de produção são diferentes, o objetivo é o mesmo da globalização.

Evidente que não se perde a divisão do mundo em países desenvolvidos, em desenvolvimento e subdesenvolvidos que, segundo os discursos ideológicos dominantes, colaboram mutualmente para o "bem" da humanidade. Todos os encontros sobre a natureza, a água etc. são exemplos dessas políticas de busca de caminhos para a "salvação" da humanidade.

Nada se concretiza, e a situação é cada vez mais dramática em todo o mundo. As contradições da própria lógica do capital, que necessita produzir sempre explorando mais os trabalhadores, e a possibilidade da circulação das mercadorias e seu consumo se efetivaram em níveis satisfatórios cada vez que se distanciam da realidade. A crise estrutural do capital não consegue mais superar as perdas que as crises cíclicas e o próprio sistema produzem, mesmo com o aumento da exploração do trabalho em nível mundial.

Afloram, então, as contradições das forças produtivas e das relações de produção do modo de produção capitalista.

Por outras palavras, relativo a um determinado sistema socioeconômico e político, estamos a falar acerca da diferença vital entre as mais ou menos frequentes crises na política, por oposição às crises na política, por oposição às crises da própria modalidade de política estabelecida, com requisitos qualitativamente diferentes para a possível solução. É com as últimas que estamos hoje preocupados. (Mészáros in Tonet, 2019)

O funcionamento dessas contradições (condições de produção restritas) ${ }^{2}$ no momento atual precisa ser entendido para que se possa chegar ao real da história e compreender como a particularidade dessas contradições vem afetando o Brasil desde a década de 70 do século passado, sobretudo após a crise que se iniciou em 2008 nos EUA. Essas são as condições de produção que permitem uma análise de discurso do mundo contemporâneo, mantendo-se as especificidades. Por esse motivo não há como realizar análises do real da história sem discutir a produção e a reprodução da vida em cada momento histórico em cada sociabilidade.

A forma de trabalho das sociabilidades constitui a protoforma de todas as relações sociais, mas isso não quer dizer que não haja outras determinações importantíssimas, como, por exemplo, a política e a educação. A produção no mundo atual é realizada pela compra da força de trabalho, que gera a mais-valia, que explora o trabalhador. Há de ser sempre a base de qualquer relação das sociedades, da mesma forma que o trabalho escravo era a base das sociedades escravistas.

Como diz Lukács:

Como já vimos muitas vezes em outros contextos, à economia cabe a função ontologicamente primária, fundante. E, apesar de já dito também muitas vezes, vale a pena sublinhá-lo mais uma vez: em tal prioridade ontológica não está contida nenhuma hierarquia de valor. (Lukács, 2013, p. 117)

2 As condições de produção restritas se refere ao momento histórico que se está analisando com suas contradições e não as descrições desse momento. 
Para que as relações capitalistas se desenvolvessem foram necessárias mudanças na forma do Estado. Chegou-se então à democracia burguesa, controlada por esse sistema do capital, que proporcionou aos trabalhadores dos países desenvolvidos e em desenvolvimento melhores condições de vida e mais liberdade por um determinado tempo. No entanto, as contradições que levam o sistema às crises cíclicas geraram a necessidade de se valer de outras formas de empreender a democracia, sempre do ponto de vista da burguesia.

Fala-se aqui das diversas mudanças que os órgãos de governo em todo o mundo sofreram, principalmente na forma de gerir a economia, com a criação de instituições separadas das outras formas de governo e ampla liberdade para conduzir a economia dos países, a exemplo dos Bancos Centrais. Mészáros resume de forma didática as características da crise estrutural do capitalismo, a seguir:

A novidade histórica da crise atual é manifestada através de quatro aspectos principais.

1. O seu caráter é universal, em vez de ser restrito a uma esfera particular (por exemplo, financeira, comercial, ou afetando apenas este ou aquele ramo específico da produção, ou que se aplica a este ou àquele outro tipo de trabalho, com seu alcance específico de habilidades ou graus de produtividade etc.);

2. O seu ânimo é verdadeiramente global (no sentido literal e ameaçador do termo), em vez de confinado a um conjunto particular de países (como foram todas as grandes crises ocorridas no passado);

3. A sua escala temporal é prolongada, contínua - se preferem, permanentes - ao invés de limitada e cíclica, como acabaram por ser todas as anteriores crise do capital.

4. O seu modo de evolução pode ser chamado de rastejante - em contraste com as mais espetaculares e dramáticas erupções e colapsos do passado - enquanto se soma à condição de que mesmo as convulsões mais veementes ou violentas não podem ser excluídas relativamente ao futuro; quer dizer, quando a complexa maquinaria agora em atividade empenhada na "gestão da crise" e no mais ou menos temporário "deslocamento das contradições em crescimento ficar sem vapor. (Mészáros, 2002, p. 104)

Percebe-se, segundo Mészáros, que a situação do sistema capitalista tem de se desdobrar para manter a lucratividade; para isso, o alvo principal são os trabalhadores. As manifestações em todo o mundo demonstram que isso ocorre cada vez mais.

Por outro lado, como afirma Tonet (2019, p. 13) ao se referir à regulação dos mercados:

Por isso mesmo, se mostrou necessário estabelecer limites essencialmente constituídos pelos aparatos jurídico-políticos estatais. A concorrência não é anulada, já que isso significaria a morte do capitalismo, mas regulamentada. É este aparato jurídico-político, sempre movente e movido, que cria a ilusão de que é o Estado, com esse aparato jurídico-político, que cria a sociedade como sociedade, vale dizer, como algo que pode reproduzir-se de maneira organizada. Este conjunto de instrumentos jurídicos e políticos constitui a democracia moderna. Ela tem seu fundamento ontológico no capital e, portanto, jamais pode opor-se radicalmente a ele. Deste modo, não é difícil compreender tanto a existência quanto as limitações dos choques que acontecem entre capital e democracia.

A alienação decorrente da própria lógica do capital e o papel da ideologia criam a cena necessária para a implementação de "mudanças" que não podem deixar de se consolidar para toda a sociedade, mas que não interessam aos trabalhadores. Elas acabam sendo efetivadas sob a roupagem de propostas carismáticas feitas em épocas de eleições mediante os órgãos políticos, e sempre em nome da democracia. 
Dessa forma, a democracia se tornou uma troca de benefícios pessoais entre os políticos. Como diz Tonet (2019): “Constata-se, na verdade, que a política democrática se transformou em um balcão de negócios”. Para Marx (1995, p. 79), “onde há partidos políticos, cada um encontra o fundamento de qualquer mal no fato de que não ele, mas seu partido adversário, acha-se ao leme do Estado".

Seguindo essa lógica, há de se entender que a crise política que se instala após a reeleição da presidenta Dilma é uma das consequências de mais uma crise do capital; ela não se põe por si mesma, mas dialeticamente interfere nas medidas a serem tomadas pelo Estado, no discurso para "salvar" a economia brasileira e para tentar minimizar as perdas do capital. Como diz Marx (1995, p. 80): “Com efeito, esta dilaceração, esta infâmia, esta escravidão da sociedade civil, é o fundamento natural onde se apoia o Estado moderno, assim como a sociedade civil da escravidão era o fundamento no qual se apoiava o Estado antigo".

Mais uma vez é necessário ressaltar a função que o Estado tem em todas as sociedades de classes: a manutenção do sistema de exploração do trabalho. Evidentemente está-se a analisar de forma histórica e dialética, o que traz como consequência a luta entre as classes e a necessidade de se manter um discurso hegemônico que funcione como o único possível para se sair da crise e resolver os problemas de todos.

O poder da ideologia tem um lugar primordial nessas fases de crises. Segundo Mészáros (2009), há uma necessidade premente de controle social, a depender da situação de cada sociabilidade.

O reverso da medalha da "tolerância repressiva" é a "tolerância reprimida". Ambas demarcam os limites de sistemas sociais incapazes de satisfazer a necessidade de mudança social num determinado período histórico. (Mészáros, 2009, p. 61)

Esses são os limites que podem surgir em qualquer sociabilidade entre democracia burguesa ou ditadura; eles vão sendo avaliados conforme a lógica capitalista. Nesse entremeio tem-se a democracia do faz de conta, isto é, com apenas eleições para parecer que continua a se dirigir a todos, e uma "tolerância reprimida" para todos os conflitos de classe. Como está acontecendo no Brasil após o golpe de 2016.

\section{O processo do enfrentamento: o domínio da irracionalidade}

O irracionalismo é a forma com que a burguesia cria e expõe suas ideias necessárias à manutenção da ordem do sistema que lhe determinou a sua classe como dominante. Nesse sentido, nada que a burguesia efetive deve ser novidade para aqueles que têm uma visão crítica radical sobre as relações sociais no sistema capitalista.

Lukács demostra que há uma grande parte dos críticos desse sistema que sucumbem ao irracionalismo e criam uma perspectiva que não ultrapassa a fronteira da ordem capitalista, tendo como consequência uma perspectiva de luta que não vislumbra um para além das relações capitalistas e não consegue perceber o lugar do Estado contemporâneo como construção do capitalismo.

No texto "Grande Hotel Abismo", escrito em 1933, sob as condições econômicas e sociais que levariam ao fascismo, ao nazismo e, finalmente à Segunda Guerra Mundial, Lukács analisa o comportamento dos intelectuais nesse momento da história: 
La intelectualidad, aquel sector de la sociedad que, como consecuencia de la división social del trabajo, ejerce la producción y propaganda de la ideología como actividad vital, como base espiritual y material (lleva su propria existencia con rapidez y sensibilidad extraordinarias frente a todos los cambios de la realidad material de la sociedad). (Lukács, 2014, p. 13)

Nesses momentos históricos combativos, para o autor, a maioria dos intelectuais acaba percebendo as mudanças da sociedade apenas como mudanças ideológicas.

El productor de la ideología burguesa, como consecuencia de las necesidades materiales de su situación social, en la ilusión de que los cambios de la sociedad son, por su propria índole, cambios ideológicos y en última instancia resultados de los cambios ideológicos; de esta ilusión surge también el liderazgo social concreto de su grupo. (Lukács, 2014, p. 13)

Para Lukács, a pequena burguesia entra nessas condições com uma tendência que pode aprovar a revolução, e mais adiante, a contrarrevolução. Quando as mudanças propostas pelas lutas de classes se acirram, ela tende a apoiar uma negação das ações mais radicais propostas pelos trabalhadores, gabando-se de ter implementado ideologicamente o que deve ser feito, sem a necessidade de entender que as formas ideológicas predominantes pertencem à burguesia. Assim se fazem os períodos de crise econômica, como demonstra Lukács (2014, p. 14):

En la ideología, en especial en los productores de ideologías, esta situación se refleja en el hecho de que se veen obligados a enfrentarse de modo intenso con la ideología de la clase revolucionaria, incluso a incorporar elementos de esta ideología dentro de la propria y a transformar su propria ideología, como se ella fuera la auténtica realización de las aspiraciones progresistas de la sociedad.

Essa situação fortalece os dominantes e exploradores, que ocultam as verdadeiras relações de classes, contribuindo para que haja um período de grande demagogia, produzindo uma ideologia de pessimismo e de desespero que acaba por gerar figuras políticas necessárias ao capitalismo. A eleição de 2018 é um exemplo de como o Capital age, apoiando uma candidatura mais maleável a suas necessidades. $\mathrm{O}$ capital não tem uma máscara definida, tanto no sentido de apoiar a ditadura como a democracia, bem como qualquer representante no governo que lhe proporcione continuar explorando a mais-valia.

Como diz Lukács, (2014, p. 15): "Y cuanto más ostenciblemente aparecen las crisis del sistema capitalista, tanto más ostensible se vuelve la barbárie en las formas fascistas de mantener la explotación que ejerce el capital monopólico".

Nesse momento, é fundamental para a burguesia que esse tipo de intelectual se coloque como um crítico da crise, mas não do capitalismo. Buscam-se essas pessoas e as idealizam como alguém que poderá salvar a sociedade, mas não esclarecem para todos como isso pode ser feito, principalmente para os trabalhadores. As grandes mídias estarão a postos para inaugurar programas de entrevistas e debates em que esses intelectuais se apresentam como salvadores.

Os intelectuais, em princípio, criticam a sociedade, mas como não conseguem perceber a realidade, suas intenções não superam a realidade, pelo contrário, fortalecem a visão burguesa da vida. Pois há por parte da burguesia um limite claro entre o "tolerável" e o "intolerável”, gerando uma repressão para os últimos e uma depreciação de seus atos. 
Aquel límite invisible en este ámbito que separa lo permitido de lo prohibido, lo tolerable de lo intolerable para la burguesia, lo opuesto - desde una perspectiva objetiva - solo en apariencia a lo auténticamente revolucionario se convierte en límite de la toleráncia material por parte de la burguesia, en cuestión de la existéncia material de este sector intelectual. (Lukács, 2014, p. 19)

A forma de a burguesia enfrentar a crítica varia a depender do nível da luta de classes. Em momentos sem crise aguda na economia, cada vez mais difíceis de acontecer, dada a crise estrutural do sistema capitalista, a burguesia pode se entregar à tarefa de abrandar a represália. Ao contrário, será sempre violenta em outros momentos. Isso é o que está acontecendo no mundo todo, com as guerras ditas localizadas e suas consequências, os emigrantes.

Os intelectuais da burguesia, principalmente aqueles que se permitem criticar diretamente, mas que não saem do âmbito da sociedade capitalista, não trazem as condições de produção reais das relações de produção e sua implicação ideológica. Na verdade, mantêm para o capitalismo a visão de uma democracia que já não pode se sustentar sem essas críticas ideológicas. No entanto, a depender das condições históricas futuras, também serão banidos de seus lugares. A história da Segunda Guerra Mundial esclarece a maneira de agir do sistema capitalista.

\section{O irracionalismo no Brasil}

O irracionalismo é intrínseco ao sistema do capital. Vive-se hoje um momento em que ele se aprofunda por necessidade do sistema. Não pensar criticamente é a base que sustenta o irracionalismo. A língua de metal que é disseminada nas mídias é o exemplo melhor dessa forma de formar as mentalidades: muita informação sem nenhum aprofundamento. A maioria não lê nada que seja "muito grande". Há então afirmações que refletem esse momento, colocadas em camisetas que na maioria das vezes não são completamente entendidas, principalmente quando em língua estrangeiras, mas que passeiam pelas cidades e são assimiladas por muitos.

Eu e Marianne escrevemos um artigo que analisava os dizeres de uma camisa muito usada nas praias de Alagoas, provavelmente em todo o Brasil. Eis como analisamos: como força de trabalho, como mercadoria.

\section{EU QUERO SER \\ FELIZ \\ EU NÃO QUERO TER \\ RAZÃO}

O sujeito contemporâneo, submetido ao sujeito do capital, por isso estranhado em sua própria constituição subjetiva. Segundo Silveira (1989, p. 52), "a dimensão da subjetividade envolvida em sua relação alienada e estranhada com os outros é que o próprio sujeito se encontra como trabalhador, quer dizer, como mercadoria. Esse estranhamento que tem sua fonte no estranhamento do trabalho nas sociedades capitalistas, produz uma subjetividade voltada para si própria, indiferente aos ditames sociais, não participativa eticamente e, necessariamente, violenta. (Mariani e Magalhães, 2011, p. 135) 
Pêcheux, nesse mesmo caminho, já afirmara que a exaltação à autonomia, que aprisiona todos os aspectos da subjetividade, "compreende-se, pois que o idealismo não é, de início, uma posição epistemológica, mas, sobretudo, o funcionamento espontâneo da forma-sujeito, por meio do qual se dá como essência do real aquilo que constitui seu efeito representado por um sujeito" (Pêcheux, 1988, p. 163).

Este ano (2019) nos deparamos com outra camiseta, que dizia o seguinte:

\section{SE EU NÃO ME LEMBRO \\ É PORQUE NÃO FIZ.}

Dessa forma, entramos novamente na área do irracionalismo do subjetivo, no sentido de que o real do fato não importa, só é verdade aquilo que o sujeito traz na lembrança. Aqui não estamos nos referindo à memória, mas à lembrança individual. Explicita-se a efetividade de dizeres que exaltam a possibilidade do indivíduo tão divulgado em discurso que diz: "VOCÊ PODE... TUDO". O discurso traz a ideologia liberal que dá ao indivíduo uma potencialidade que na verdade ele não tem. Cobra dele quando ele não consegue fazer o que diz "que pode".

VOCÊ PODE é o enunciado repetido de diversas maneiras na contemporaneidade. Com isso as falhas que a determinação ideológica provoca, pois não há tudo para todos na sociabilidade. Surge, então, o sujeito que decide, que escolhe, como se não houvesse nenhuma determinação que o conduza e limite. Principalmente, há o silenciamento completo da impossibilidade, em sociedades de classes antagônicas, de se resolver os problemas cotidianos mais elementares, da maioria das populações do mundo inteiro. Paralelamente, a incompletude do sujeito e a incompletude da língua são também apagadas, e as afirmações desse tipo você pode funcionam como mecanismo ideológico do sistema capitalista, para, mais uma vez, imputar à subjetividade contemporânea uma busca incessante de prazer absoluto, o que se associa à frustração de não encontrá-la nunca. (Magalhães, no prelo, 2019)

Lukács mostra como a irracionalidade é uma força ideológica usada sempre pela burguesia. Tem como objetivo barrar o pensamento, por ser algo nocivo ao cotidiano das pessoas, levando as pessoas a decidir sua vida pelas emoções, com a máxima repetida no cotidiano, pelas pessoas e pelas mídias:

\section{PERGUNTE AO SEU CORAÇÃO E DECIDA.}

A depreciação do entendimento e da razão, a glorificação da intuição, a gnosiologia aristocrática, a recusa do progresso sócio-histórico, a criação de mitos são, entre outros, motivos que encontramos em quase todo pensador irracionalista. (Lukács, no prelo, p. 10)

Paralelamente, na política as campanhas eleitorais prometem tudo de bom para o povo, sobretudo uma nova forma de governar que vai fazer o Brasil alcançar outro patamar na ordem mundial. As eleições se tornaram um complexo de fake news. As afirmações feitas nas propagandas não podem ser cumpridas no sistema capitalista, mas a maioria não sabe disso e então vota.

Uma grande massa de intelectuais de direita aprova as medidas. Os da esquerda não apoiam, mas não lutam por outras medidas radicais que quebrariam a possibilidade de 
avanço da exploração dos trabalhadores. Não podem, dentro do jogo eleitoral da democracia burguesa, propor o fim da exploração do trabalhador.

Enquanto se discutem as formas autoritárias e irracionais dos presidentes eleitos democraticamente como o americano e o brasileiro, as leis que acabam com o trabalho assalariado formal, com a natureza, contra as minorias etc., são votadas "democraticamente". A ideologia funciona dessa forma e não permite que a população em geral compreenda o que se está fazendo para explorar cada vez mais o trabalhador.

A reforma trabalhista votada no período do presidente que assumiu depois do golpe de 2016 já havia preparando o terreno para que as garantias trabalhistas fossem retiradas, sendo exaltadas as relações de trabalho informais. Surgiu então o discurso repetido à exaustão pela Presidência e pelas mídias: "o trabalhador quer garantias ou emprego? Com garantias não há emprego".

Os organismos da terceirização, ao realizarem essa adequação, estabelecem uma relação entre o trabalho informal e a produção capitalista, suscitando um segmento moderno dessa forma de trabalho, que tende a se generalizar pela natureza flexível que o caracteriza. Nesses termos, o trabalho informal deixaria de ser intersticial ou suplementar, para, cada vez mais, tender a tornar-se parte do núcleo capitalista. (Tavares, 2004, p. 131)

Embora todos os trabalhadores sejam atingidos por essa nova lei, as mulheres são as mais prejudicadas, pois o trabalho que mais ocupa as mulheres no Brasil é o doméstico remunerado, que se transforma em trabalho de diarista, sem nenhuma garantia trabalhista.

As mídias fazem "propaganda" dessas leis, apresentando casos de mulheres que como diaristas conseguiram comprar casa e viver melhor. Ocultam que quando não puderem trabalhar mais, não terão como se sustentar; ao mesmo tempo, criticam as barbaridades dos poderes "democráticos", achando que eles são os únicos culpados, e não denunciam que essa é uma das formas de a ideologia burguesa funcionar em tempos de irracionalidade. Nada é aprofundado; as notícias são apresentadas com algum comentário que não passa de opinião de jornalistas.

No texto "Destruição da Razão", Lukács discute o papel da intelectualidade - especificamente, o da intelectualidade crítica - e as relações de exploração na Alemanha que culminaram na Segunda Guerra Mundial, um momento também de crise do sistema capitalista. O autor coloca algumas premissas fundamentais para a apreensão do real. Enfatiza que nenhum pensamento, inclusive o filosófico e o estético, surge sem se acha vinculado, embora com várias mediações, às lutas de classes.

Queremos demonstrar, pelo contrário, que as diferentes etapas do irracionalismo sugiram como respostas reacionárias a problemas das lutas de classes. O conteúdo, a forma, o método, o tom etc. de sua reação contra o progresso na sociedade não são determinados por tal dialética interna própria ao pensamento, mas, sobretudo, pelo adversário, pelas condições de luta, que são impostas à bourgeoisie reacionária. Isso precisa ser fixado como princípio básico do desenvolvimento do irracionalismo. (Lukács, no prelo, p. 10)

Percebe-se então que a luta se dá a partir do que é ditado pela burguesia, e não pela ótica dos trabalhadores. Os trabalhadores nesses momentos estão sempre resistindo, mas nunca lutando pela destruição da exploração. 
Conforme Lukács (no prelo, p. 19):

Que nenhum pensamento, numa sociedade de classes, surge sem estar vinculado, embora com várias mediações, com as lutas de classes. Também aqui é nítida a atitude fundamental do irracionalismo, em contraposição à dialética. Uma tese fundamental do materialismo dialético é que a práxis constitui o critério da verdade teórica.

Esse é o lugar em que a AD pecheutiana deve estar sempre, assinalando que o sujeito do discurso ocupa um lugar nas lutas de classes e que, sempre, o seu discurso tem efeitos de discurso a partir dessa filiação às formações ideológicas e discursivas.

\section{Para concluir: neste momento}

Como concluir algo que não está ainda concluído? Difícil, para não dizer impossível. Há apenas uma prospecção colocada como título de um livro de Mészáros, Socialismo ou Barbárie, isto é: ou se luta por uma igualdade de direitos como norma da sociedade, criando uma subjetividade que tenha a humanidade como centro da vida de todos, ou os filmes que mostram as atrocidades entre os homens para a sobrevivência será e/ou serão a forma de vida no planeta.

Para isso, a $\mathrm{AD}$ precisa perceber que o foco das lutas não pode se restringir à política, mas deve estender-se às relações de produção, como diz Pêcheux, seguindo Marx.

A crítica do irracionalismo burguês é essencial para a mudança do caminho da crítica, o que tanto absorveu Pêcheux em seus estudos. Não é mais possível dizer-se pecheutiano e não captar o real da história em suas contradições fundamentais. A barbárie já está no nosso meio, ou melhor, sempre esteve, mas ainda não domina tudo e todos. Nossos trabalhos científicos devem conter sempre a crítica ao capitalismo, e não uma tentativa de torná-lo humano, pois isso é impossível e constitui um desconhecimento de sua lógica.

\section{Referências}

COURTINE, Jean-Jacques. Metamorfose do Discurso Político: derivas da fala pública. São Carlos: Claraluz, 2006.

LUKÀCS, Georg. Gran Hotel “Abismo” In: Anuário Lukács 2014. São Paulo: Instituto Lukács, 2014.

MAGALHAES, Belmira R. Você Pode: A exaltação da individualidade autônoma e poderosa no discurso contemporâneo. 2019, no prelo.

MARIANI, B. e MAGALHÃES, Belmira. "Eu quero ser feliz" O SUJEITO, Seus Desejos e a Ideologia. In: INDURSKY, Freda, MITTMANN, Solange; FERREIRA, Maria Cristina L. (orgs) Memória e História na/da Análise do Discurso. Campinas: Mercado de Letras, 2011.

MARX. Karl. Glosas críticas marginais ao artigo O rei da Prússia e a reforma social de um Prussiano. Projeto Joaquim de Oliveira, In: Revista Praxis, Belo Horizonte, n. 5, 1995. MÉSZÁROS, I. A Crítica Estrutural da Política. Discurso de Abertura do $13^{\circ}$ Congresso Nacional dos Magistrados da Justiça do Trabalho, em Maceió, 4 de maio de 2006. 
. Para Além do Capital. São Paulo: BoiTempo Editorial, 2002 . A Montanha que Devemos Conquistar. São Paulo: BoiTempo Editorial, 2015. PÊCHEUX, Michel. Semântica e discurso: uma crítica à afirmação do óbvio. Campinas: Editora da Unicamp, $4^{\text {a }}$ edição, 2009.

TAVARES, M. R. Os Fios (IN) visíveis da Produção Capitalista: Informalidade e Precarização do Trabalho. São Paulo: Ed. Cortez, 2004.

TONET, I; NASCIMENTO, A. Descaminhos da esquerda: Da Centralidade da Política à centralidade do trabalho. São Paulo: Ed. Alfa-Omega, 2009. 2019.

. O fim da Democracia Moderna. In: Revista Novos Rumos, São Paulo, v. 55 n. 2,

Recebido em: 07/05/2019; Aceito em: 20/05/2019 